\begin{tabular}{|c|c|}
\hline & $\begin{array}{l}\text { International Journal of Trend in Scientific } \\
\text { Research and Development (IJTSRD) }\end{array}$ \\
\hline 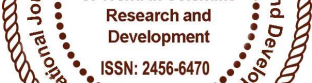 & International Open Access Journal \\
\hline 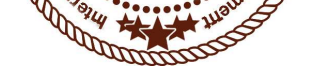 & ISSN No: 2456 - 6470 | www.ijtsrd.com | Volume - 2 | Issue - 2 \\
\hline
\end{tabular}

\title{
Improving Surface Finishing Quality by Using Radius Carbide Tips
}

\section{Yeddula Manohar Reddy \\ P. G. Scholar}

Sri Venkateswara Institute of

Technology, Anantapuram,

Andhra Pradesh, India

\author{
Mr. K. Pavan Kumar Reddy \\ Assistant Professor \\ Sri Venkateswara Institute of \\ Technology, Anantapuram, \\ Andhra Pradesh, India
}

\author{
Jayam Sree Hari \\ Assistant Professor \\ Sri Venkateswara Institute of \\ Technology, Anantapuram, \\ Andhra Pradesh, India
}

\section{ABSTRACT}

In the metal cutting industry, Tip s cutter plays an important role in cutting metal to obtain the various required shapes and sizes. It is also an essential cutting tool for the engineering productions in the various aspects of engineering industries. For example, Automobile, Aerospace, Precision Engineering, Metal Stamping and Plastic Molding industries, therefore Tip sis the most common and widely used type of milling cutters where the demand is very huge. There are many different brands and types of Tips cutters available in the market, which manufacture from Japan, America, Europe, Korea, India, Taiwan and China, etc. The increasing competition in the market region spurs the various manufacturers to constantly develop many different kinds of high performances Tips cutters to cater the huge demand in the various aspect of engineering industries which can speed up the production time, processes and also reduce the production and lab our cost.

\section{Keywords: Machining, Friction and Contact Model}

\section{INTRODUCTION}

This project is to conduct a research and develop a Multi-Purpose Carbide Tipsto suit all kinds of cutting processes and engineering manufacturing works, which will uncover the background information on different kinds of Tips structures, tool materials and various surface treatments on the cutter. Research will also be conducted on the different types of cutting operations, cutting conditions, work materials and its characteristics used commonly in manufacturing processes. Analysis and troubleshooting on the common problems faced by different types of Tips cutters during manufacturing processes will also be studied by conducting test cut on various work materials to justify its cutting performances and cutting conditions. Upon achieving all these technical information, I will start designing and constructing of the Multi-Purpose Carbide End mill.

Once the Multi-Purpose Carbide Tips prototype is produced, test cut on the Tipswill be conducted to justify its cutting performances and condition on various work materials. Lastly, I will analysis and compare the Multi-Purpose Carbide Tipstest results against the conventional End mills to verify its cutting performances, cutting conditions and tool life.

\section{LITERATURE REVIEW}

An effective methodology is needed to obtain the normalized minimum chip thickness. Liu et al. [1] has achieved this by making use of the thermomechanical properties ofbasic molecular mechanics and the theory of friction. The primary objective is to extend the knowledge of the minimum chip thickness values for other materials when they are subjected to different cutting conditions. Shear strain and strain rate with cutting temperature are important properties which were evaluated using these techniques. The cutting temperatures at both job-chip interface and 
tool-chip interface were considered. To facilitate the formulations, was used a model of slip-line field. This model represents the finished edge tool radius. To determine the conditions for the transition from plowing to Microcutting, the equation is used Kragelskii-Drujanov. To evaluate the effective flow stress at high strain rate, high temperature and high voltage, the model of Johnson-Cook (aluminum alloy) and the model Oxley (for carbon steel) were combined. For the experimental design, the materials used are steel 1040 and Al 6082-T6. There are two contrasting ways in which has increased the cutting speed affects minimum chip thickness. In the first place, the cutting temperature increases with increased cutting speed leading to an increase of the effect thermal softening and consequent increase in the ductility. Thus, the minimum chip thickness increases too. Secondly, with increase of speed of cutting, deformation and effectively increase the speed of deformation which increases the effect of work hardening. Therefore, the minimum chip thickness and ductility decrease. It is seen that for the machining of carbon steels, chip of minimum thickness increases with the speed of the edge of the cutting tool and increases distance. Again, the higher the carbon content of the steels, the higher the minimum chip thickness. While the processing of aluminum, it is seen that the values of minimum thickness of chips remains constant over a wide range of cutting speeds and radio edge of the tool. Thus, for the machining of carbon steels, high-speed are not used while for the aluminum alloys of machining, high speeds are used for a higher productivity.

\section{PROJECT METHODOLOGY}

Micro-grain end mills designed for cutting steel are Milling is a machining process in which metal is removed by a rotating multiple-tooth cutter. Each tooth removes a small amount of metal with each revolution of the spindle. AnTipsis a milling cutter, which is shank-mounted to the machine tool. It has cutting edges on the face end as well as on the periphery, and may be single or double end construction. End mills are the most common and widely used type of milling cutters.

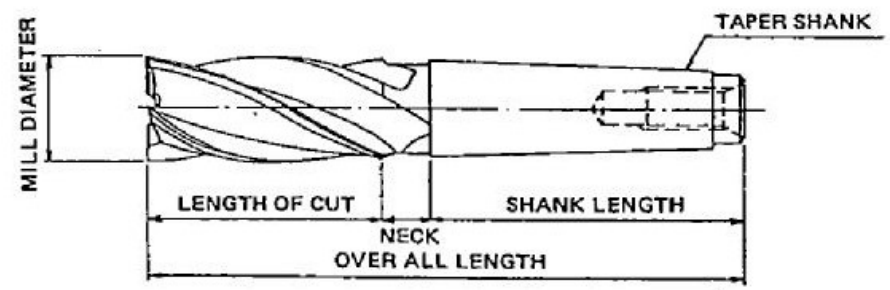

Fig.2. Taper Shank End mill

\section{Selection of Cutting Fluids}

Milling process can be very complicated work and it significantly affect machined surface accuracy, tool life, cutting torque, etc. Different types of cutting fluids also affect it. Cutting fluids have basic three functions:

$>$ Cooling

$>$ Lubrication

$>$ Anti-welding

For the selection of cutting fluids, we must take the following three points into consideration:

To make tool life longer

To get better surface finish

To get higher efficiency of operation

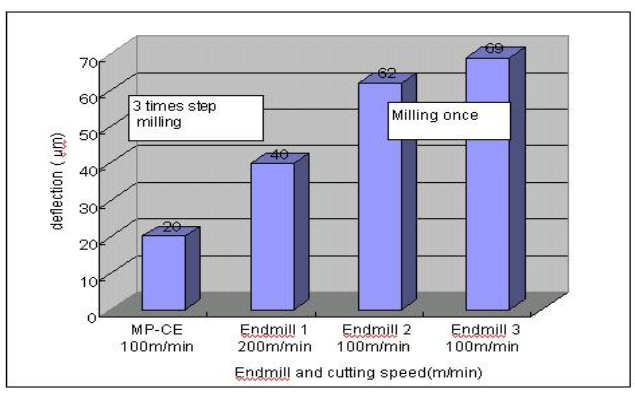

Fig.63. Comparison of the deflection

\section{RESULT}

The third test data explains on the comparison of the Multi Purpose Carbide Tipsagainst various general Tipson the deflection rate. From the figure above, it shows that Multi Purpose Carbide Tipsis performing three times step-milling operation, while the other general End mills are performing one time milling operation.

The results obtained from the figure shows that the Multi Purpose Carbide Tipshas the lowest deflection 
rates compare to the other three general End mills, while they are having the similar cutting speed.

\section{Test data 4}

The table below shows on the detailed information of the Multi Purpose Carbide Tipsagainst the general long series Tip swhile putting on test.

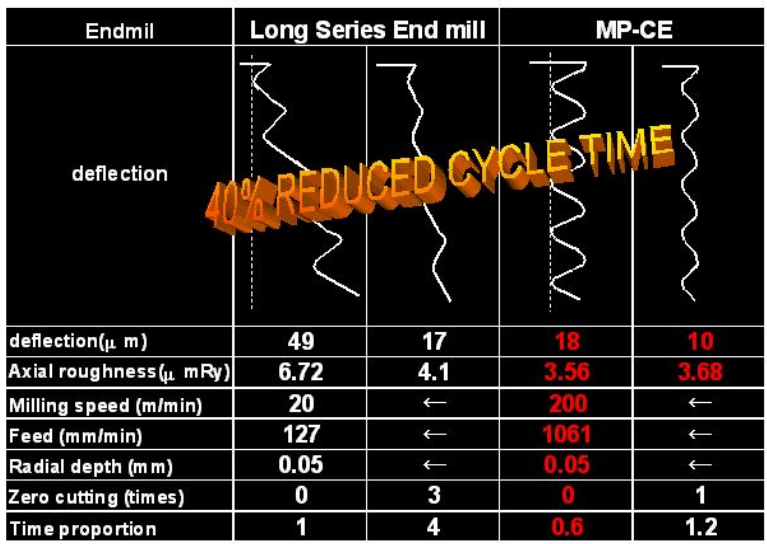

Table 16. Cycle Time reduction

\section{REFARENCE}

1) Cutting Characteristics of Carbide End mills; Kitaura, Seiichiro (Akashi Plant); Source: KOBELCO Technology Review, n 17, Apr, 1994, p 16-19

2) TIPS ON CHOOSING/USING END MILLS; Rakowski, Leo R.; Source: Machine and Tool Blue Book, v75, n 1, Jan, 1980, p 60-72

3) OSG END MILLS TECHNICAL GUIDE; Source: OSG MFG. Company \& OSG Corporation, Toyokawa, Japan, 1982.

4) Milling Cutters and End Mills; Source: The American Society of Mechanical Engineers, United Engineering Center, ANSI /ASME B94.19, 1985

5) Mechanical Behavior of Materials; Michael, B. Bever; Source: McGraw Hill International Editions, USA, 1990.

The results obtained show that the Multi Purpose Carbide Tip sis much better quality than general long series Tip sin various aspect. While having the same radial depth of cutting, it shows that the Multi Purpose Carbide Tip sis operating at high feed and speed milling.

The deflection rate and axial roughness is tremendously better than the general long series End mill, which in terms, of having $40 \%$ reduced in cycle time.

\section{CONCLUSIONS}

In this thesis, an investigation of the rake contact and friction behaviors in metal cutting operations is performed. The friction behavior in metal cutting operations is analyzed using a thermo mechanical cutting process model that represents the contact on the rake face by sticking and sliding regions.

The total contact length increases by the feed rate and decreases by the cutting speed.

$>$ The apparent friction coefficient strongly depends on the relative length of the sticking and sliding zones, and sliding friction coefficient. It shows that the apparent friction coefficient is always smaller than the sliding friction coefficient. 